05;06

\title{
Влияние диффузионных барьеров на емкостные свойства композитных анодов состава $\mathrm{Si}-\mathrm{CuSi}-\mathrm{Cu}$
}

\author{
(ㄱ Э.Ю. Бучин ${ }^{1}$, А.А. Мироненко ${ }^{2}$, В.В. Наумов ${ }^{2}$, А.С. Рудый ${ }^{1}$ \\ ${ }^{1}$ Ярославский филлиал Физико-технологического института им. К.А. Валиева РАН, Ярославль, Россия \\ ${ }^{2}$ Ярославский государственный университет им. П.Г. Демидова, Ярославль, Россия \\ E-mail: imi.buchin@rambler.ru
}

Поступило в Редакцию 21 мая 2020 г.

В окончательной редакции 21 мая 2020г.

Принято к публикации 12 июня 2020 г.

\begin{abstract}
В качестве анодного материала для жидкостных литий-ионных аккумуляторов исследованы пленочные структуры, состоящие из нескольких одинаковых модулей $[\mathrm{Co}(x) / a-\mathrm{Si}(100) / \mathrm{Cu}(70)]$, где величина $x$ изменялась от 2 до $10 \mathrm{~nm}$. Показано, что относительно толстые слои кобальта являются эффективными диффузионными барьерами для атомов кремния и меди, а также для ионов лития. Это приводит к снижению емкостных характеристик исследуемых пленок. Тонкие слои кобальта (менее $3 \mathrm{~nm}$ ), имеющие сетчатую структуру, наоборот, способствуют повышению емкостных характеристик анодных пленок. Это происходит за счет более равномерного распределения в их объеме дрейфовых каналов ионов лития, которые формируются на начальной стадии циклирования электродов.
\end{abstract}

Ключевые слова: композитная пленка, обратимая емкость анода, циклический ресурс, миграция атомов, барьерный слой, литирование, дрейфовые каналы.

DOI: 10.21883/PJTF.2020.19.50034.18389

Литий-ионные аккумуляторы в настоящее время являются наиболее широко используемыми химическими источниками тока. Большой спрос стимулирует проведение работ по дальнейшему их совершенствованию. Одним из направлений исследований является использование в качестве электродов кремниевых пленок, что обусловлено их высокой расчетной емкостью [1-3]. Однако достичь этой величины и сохранить ее при длительной работе электродов на практике пока не удается. В рамках этого направления нами были проведены исследования композитных пленок состава $\mathrm{Si}-\mathrm{CuSi}-\mathrm{Cu}$ в качестве анодного материала для жидкостных литийионных аккумуляторов [4]. При испытании экспериментальных образцов наблюдался эффект длительного интенсивного роста их удельной емкости в течение нескольких сотен циклов заряда/разряда. Эффект проявлялся при определенном составе пленок и режиме их отжига до циклирования. Эти параметры подбирались таким образом, чтобы лишь часть кремния вступала в реакцию с медью с образованием кристаллической фазы $\mathrm{Cu}_{x} \mathrm{Si}$. Силицид меди формировался в виде разветвленного кластера, который пронизывал весь объем анодной пленки и армировал ее. Остальной кремний при работе электрода взаимодействовал с ионами лития с образованием обратимых сплавов $\mathrm{Li}_{x} \mathrm{Si}$. Для объяснения эффекта была предложена феноменологическая модель, основанная на разнонаправленной миграции атомов кремния и остаточной меди в неоднородном поле упругих механических напряжений, возникающих при циклировании электрода. В результате этого массопереноса постепенно происходило изменение структуры исследуемых пленок, в том числе развитие их поверхности, что и приводило к увеличению обратимой емкости.

Целью настоящей работы является исследование влияния диффузионных барьеров, введенных в состав указанных пленок, на их емкостные свойства. В качестве таких барьеров были выбраны слои кобальта толщиной от 2 до $10 \mathrm{~nm}$. Предполагалось, что они определенным образом повлияют на массоперенос кремния, меди, а также ионов $\mathrm{Li}^{+}$в исследуемых пленках. Выбор кобальта обусловлен двумя причинами. Во-первых, он, так же как и ряд других переходных металлов (Ti, $\mathrm{Cr}, \mathrm{Cu}, \mathrm{Ni}, \mathrm{Fe}, \mathrm{Mn}, \mathrm{Sb}, \mathrm{In})$, является инертным по отношению к литию материалом [5]. Во-вторых, взаимная растворимость компонентов в бинарных системах $\mathrm{Co}-\mathrm{Si}$ и $\mathrm{Co}-\mathrm{Cu}$ очень низкая в диапазоне выбранных нами режимов отжига. Например, растворимость меди в кобальте даже при температуре $800^{\circ} \mathrm{C}$ составляет лишь единицы весовых процентов [6].

Экспериментальные аноды представляли собой многослойные пленочные структуры, состоящие из шести одинаковых модулей состава $[\mathrm{Co}(x) / a-\mathrm{Si}(100) / \mathrm{Cu}(70)]$. Толщина кобальтовых слоев изменялась в пределах от 2 до $10 \mathrm{~nm}$. Структуры осаждались методом высокочастотного магнетронного распыления соответствующих мишеней на титановую фольгу, которая далее служила в качестве токового коллектора. Суммарная толщина анодных пленок во всех образцах составляла $1 \mu \mathrm{m}$. Исходный вакуум в рабочей камере установки напыления (SCR-651 „Tetra“ Alcatel) достигал $5 \cdot 10^{-7} \mathrm{mbar}$ при напуске плазмообразующего газа (Ar) он поддерживался на уровне $2 \cdot 10^{-3}$ mbar. Затем образцы подвергались вакуумному отжигу $\left(10^{-6} \mathrm{mbar}\right)$ 


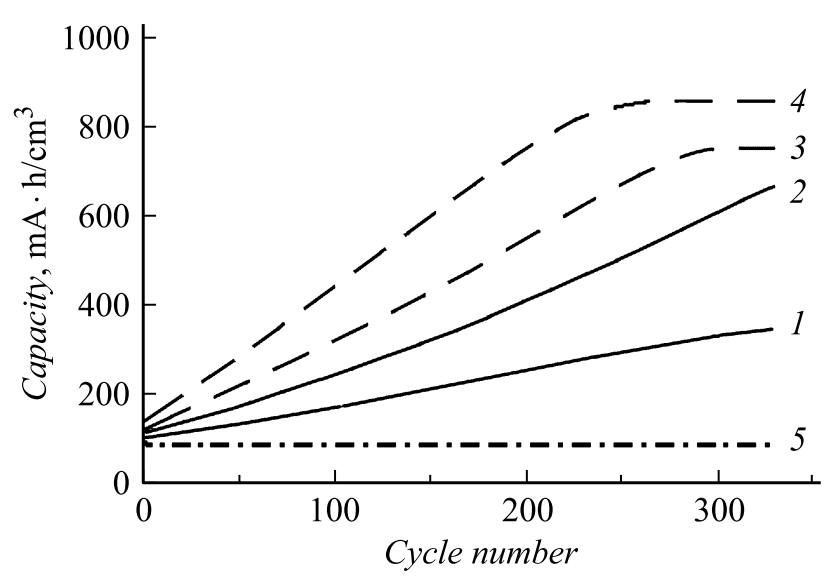

Рис. 1. Емкостные профили экспериментальных анодов состава $[\mathrm{Co}(x) / a-\mathrm{Si}(100) / \mathrm{Cu}(70)]_{6} .1,2$ - контрольные образцы, не содержащие слоев кобальта, 3,4 - толщина слоев кобальта $2 \mathrm{~nm}, 5$ - толщина слоев кобальта $10 \mathrm{~nm} .1,3$ - образцы до циклирования отжигались при температуре $100^{\circ} \mathrm{C}, 2,4,5-$ при $200^{\circ} \mathrm{C}$.

в течение $4 \mathrm{~h}$ при температурах $100-200^{\circ} \mathrm{C}$. Из полученных структур были вырезаны образцы размером $15 \times 15 \mathrm{~mm}$, электрохимические исследования которых проводились в тефлоновых ячейках, содержащих литиевые противоэлектрод и электрод сравнения. В качестве электролита использовался $1 \mathrm{M}$ раствор $\mathrm{LiPF}_{6}$ в смеси диметилкарбоната-диэтилкарбоната-этиленкарбоната, взятых в равных объемных долях. В качестве сепаратора был использован нетканый полипропилен. Электрохимические ячейки собирались в перчаточном боксе в среде сухого аргона. Их циклирование проводилось при комнатной температуре с помощью компьютеризированного стенда АЗРИВК компании „Бустер“ (Санкт-Петербург, Россия) в гальваностатическом режиме при токе $100 \mu \mathrm{A}$ в диапазоне потенциалов $0.01-2.0 \mathrm{~V}$ относительно литиевого электрода сравнения. На основе полученных данных была рассчитана удельная объемная емкость анодов.

Морфология поверхности и структура поперечных сечений образцов до и после испытаний исследовались на сканирующем электронном микроскопе (SEM) высокого разрешения „Zeiss Supra-40“. С помощью рентгеновской энергодисперсионной приставки проводился их элементный микроанализ. Рентгенографические исследования пленок выполнялись на дифрактометре ARL X'tra (Thermo Fisher Scientific) с фокусировкой по Брэггу-Брентано в режиме $(\theta-2 \theta)$-сканирования. Распределение кремния и меди по толщине пленок исследовалось с помощью вторично-ионного масс-спектрометра с времяпролетным масс-анализатором „TOF.SIMS5“. Для распыления поверхности образцов использовались пучки высокоэнергетических ионов $\mathrm{Cs}^{+}$.

На рис. 1 приведены емкостные профили пяти экспериментальных анодов. Все они имели одинаковые количества кремния и меди, однако их характеристики различались. Образцы, представленные кривыми 1 и 2, являлись контрольными, они не содержали кобальтовых слоев, но были отожжены при разных температурах: 100 и $200^{\circ} \mathrm{C}$ соответственно. В образцах, представленных кривыми 3 и 4 (отожженных в тех же режимах), в каждый модуль дополнительно были введены кобальтовые слои толщиной $2 \mathrm{~nm}$. В образце, соответствующем кривой 5 , их толщина составляла $10 \mathrm{~nm}$, его отжиг проводился при $200^{\circ} \mathrm{C}$. Как следует из этого рисунка, кривые 1-4 имели участки длительного интенсивного роста удельной емкости в течение 300 и более циклов заряда/разряда анодов. На кривой 5 такой участок отсутствовал.

При введении в структуру пленок кобальтовых слоев толщиной $2 \mathrm{~nm}$ емкость анодов существенно увеличивалась по сравнению с емкостью контрольных образцов. В структурах, отожженных при $100^{\circ} \mathrm{C}$, она повышалась более чем в 2 раза (ср. кривые 1 и 3). В образцах, отожженных при $200^{\circ} \mathrm{C}$, приращение емкости достигало $50 \%$ (кривые 2 и 4). По мере увеличения толщины кобальтовых слоев равновесный емкостный уровень анодов резко снижался (кривая 5).

Сначала обсудим, почему различаются характеристики образцов, соответствующих кривым 1 и 2. В аморфном кремнии имеется значительное количество вакансий. В процессе отжига кремний взаимодействует с
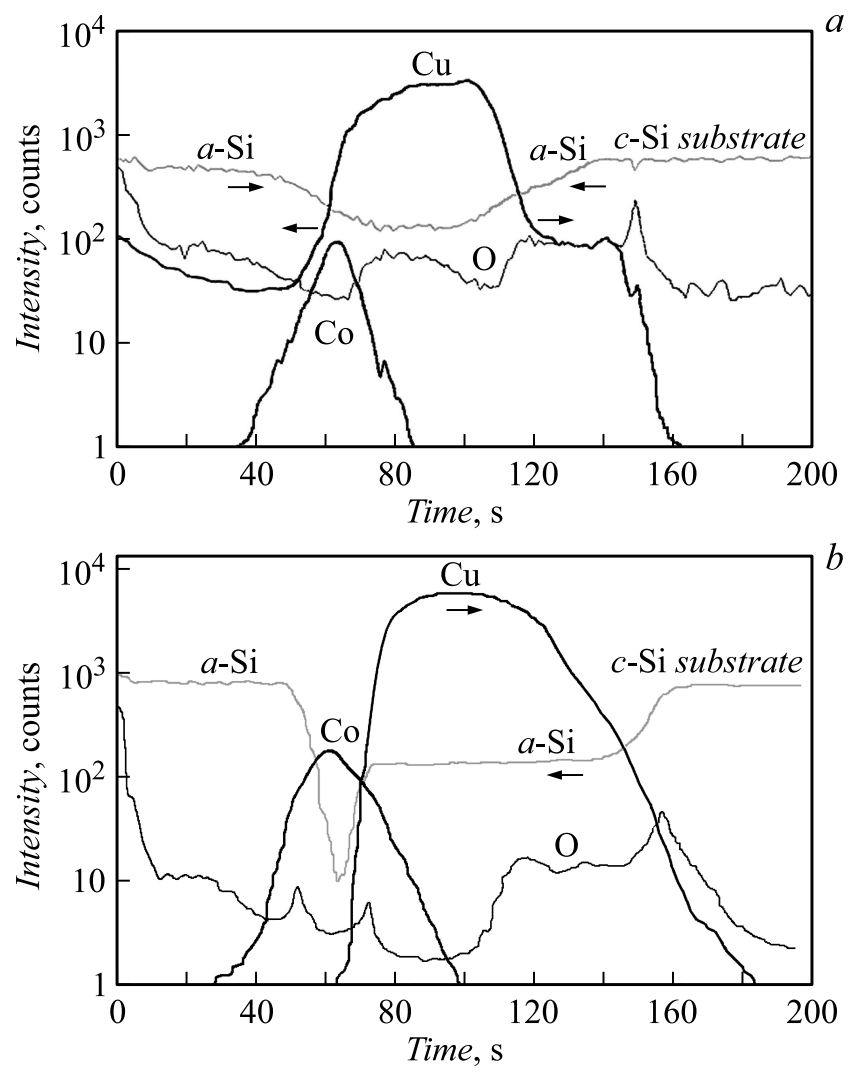

Рис. 2. SIMS-профили распределения основных компонентов в модельных структурах $[a-\mathrm{Si}(30) / \mathrm{Co}(2) / \mathrm{Cu}(30) / a-\mathrm{Si}(30)](a)$ и $[a-\mathrm{Si}(30) / \mathrm{Co}(10) / \mathrm{Cu}(30) / a-\mathrm{Si}(30)](b)$ после отжига при температуре $200^{\circ} \mathrm{C}$ в течение $4 \mathrm{~h}$. 

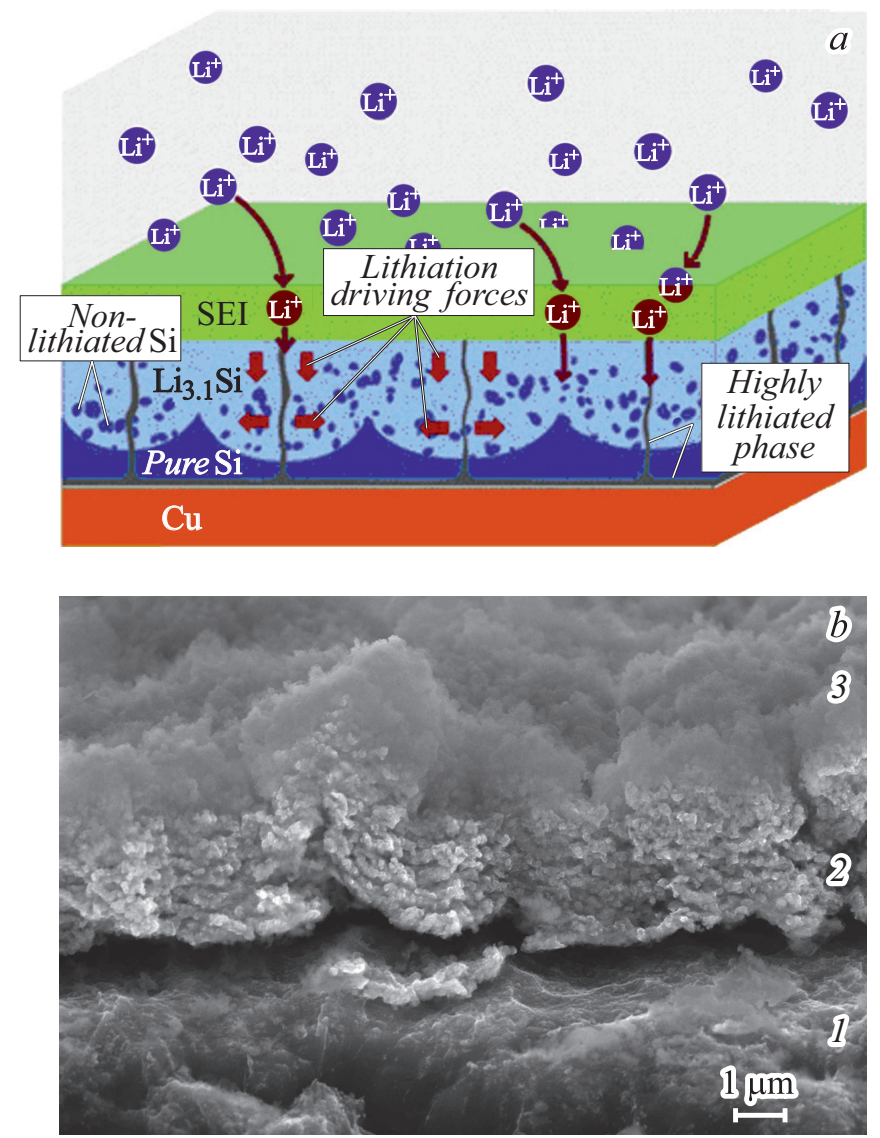

Рис. 3. $a-$ схематическое изображение механизма литирования тонкой кремниевой пленки [9] (Copyright: Американское химическое общество, 2015). $b-\mathrm{SEM-изображение} \mathrm{попереч-}$ ного сечения анодной пленки состава $[\mathrm{Co}(2) / \mathrm{Si}(100) / \mathrm{Cu}(70)]_{6}$ после 5500 циклов заряда/разряда. 1 - титановая фольга, 2 - анодная пленка, 3 - пленка SEI.

медью с образованием кристаллической фазы $\mathrm{Cu}_{x} \mathrm{Si}$. При этом часть вакансий становится избыточной, в объеме пленки на активных центрах происходит их адсорбция с образованием пустот нанометрового размера. При циклировании анода благодаря встречному массопереносу кремния и меди происходит пластическая деформация пленок, в результате которой эти пустоты постепенно „выходят“ на поверхность, повышая ее шероховатость. Увеличение площади поверхности пленок приводит к росту их обратимой емкости. Чем выше температура отжига образцов (в выбранном диапазоне), тем больше образуется вакансионных пустот. Именно поэтому у образца, отожженного при температуре $200^{\circ} \mathrm{C}$ (кривая 2), равновесный емкостный уровень выше, чем у образца, представленного кривой 1 .

Для того чтобы объяснить ход кривых 3-5, были изготовлены две модельные структуры: $[a-\operatorname{Si}(30) / \mathrm{Co}(2) /$ $\mathrm{Cu}(30) / a-\mathrm{Si}(30)] \quad$ и $\quad[a-\mathrm{Si}(30) / \mathrm{Co}(10) / \mathrm{Cu}(30) / a-\mathrm{Si}(30)]$. В качестве подложек использовались пластины монокристаллического кремния. После осаждения слоев образцы отжигались в вакууме в течение 4 h при температуре $200^{\circ}$ C. Затем был проведен их SIMS-анализ (SIMS secondary ion mass spectroscopic), результаты которого представлены на рис. 2, $a, b$. Профили распределения кислорода здесь приведены для того, чтобы обозначить положение исходных межслоевых границ. Общим признаком диаграмм являлось диффузионное уширение пиков всех компонентов пленки $(\mathrm{Co}, \mathrm{Si}$ и $\mathrm{Cu})$. В структуре, содержащей кобальтовые слои толщиной $2 \mathrm{~nm}$, это происходило симметрично как по направлению к поверхности пленки, так и в сторону подложки (рис. 2,a). Взаимной диффузии атомов кремния и меди в обе стороны ничто не препятствовало. SIMS-диаграмма образца $[a-\mathrm{Si}(30) / \mathrm{Co}(10) / \mathrm{Cu}(30) / a-\mathrm{Si}(30)]$ выглядела иначе (рис. $2, b)$. Наблюдалось несимметричное уширение пиков меди и кремния, преимущественно по направлению к подложке, т. е. слой кобальта толщиной $10 \mathrm{~nm}$ стал для их атомов непреодолимым диффузионным барьером.

Теперь обсудим вопрос, почему наличие слоев кобальта толщиной $2 \mathrm{~nm}$ приводило к увеличению обратимой емкости исследуемых анодов. Процесс литирования тонких кремниевых пленок происходит поэтапно: сначала при потенциале $0.4 \mathrm{~V}$ образуется $\mathrm{LiSi}$, затем сплавы $\mathrm{Li}_{1.7} \mathrm{Si}$ при $0.3 \mathrm{~V}, \mathrm{Li}_{3.25} \mathrm{Si}$ при $0.2 \mathrm{~V}$ и $\mathrm{Li}_{x} \mathrm{Si}(x=3.75,4.2$, 4.4) при потенциалах ниже $0.1 \mathrm{~V}$ [7]. В нашем случае $x=3.75$ (сплав $\mathrm{Li}_{15} \mathrm{Si}_{4}$ ), поскольку нижняя граница отсечки напряжения составляет 0.01 V. При экстракции ионов лития в аноде происходит частичная кристаллизация аморфного кремния [8]. Из этих кристаллитов при изменении объема пленки образуются агломераты нанометрового размера. Нарушение структурной однородности пленки приводит к тому, что электрический потенциал распределяется в ней неравномерно. При этом формируются обособленные каналы ускоренной миграции ионов $\mathrm{Li}^{+}$. Именно в них образуется максимально литированная фаза [9]. По мере удаления от этих каналов степень литирования кремния снижается (вплоть до того, что в некоторых областях он остается в исходном состоянии). Рис. 3 , $a$ хорошо иллюстрирует описанный механизм литирования тонких кремниевых пленок. На распределение миграционных каналов влияют также локальные механические напряжения, наличие фрагментов фазы $\mathrm{SiO}_{x}$ и неравномерность толщины пленки SEI (SEI - solid electrolyte interface).

Слои кобальта толщиной $2 \mathrm{~nm}$, осажденные методом магнетронного распыления, не являются сплошными, они представляют собой сетчатые структуры. Исходя из результатов анализа модельных структур такие слои не препятствуют массопереносу кремния и меди. Поэтому кривые 3 и 4 на рис. 1 являются восходящими. Кроме того, сетчатые кобальтовые слои способствуют более упорядоченному формированию каналов ускоренной миграции ионов лития. Отчасти это можно сравнить с процессом анизотропного травления кремния через набор совмещенных контактных масок. В результате использования тонких слоев кобальта количество миграционных каналов возрастает, а их распределение 
становится более однородным. Это приводит к увеличению литийактивного объема пленок и соответственно к повышению их обратимой емкости.

Кроме того, указанное структурирование способствует увеличению циклического ресурса исследуемых анодов. На рис. 3, $b$ представлено электронное изображение поперечного сечения образца, соответствующего кривой 4 на рис. 1, имеющего состав $[\mathrm{Co}(2) / \mathrm{Si}(100) / \mathrm{Cu}(70)]_{6}$, после электрохимических испытаний. В анодной пленке хорошо различимы все шесть модулей, которые даже после 5500 циклов литирования/делитирования не претерпели существенных структурных изменений.

Слои кобальта толщиной $10 \mathrm{~nm}$, осажденные методом магнетронного распыления, уже являются сплошными. Будучи интегрированными в состав исследуемых пленок, они представляют собой диффузионные барьеры, которые препятствуют миграции атомов кремния и меди. Поэтому кривая 5 на рис. 1 не имеет восходящего участка. Этот результат хорошо подкрепляет предложенную ранее физическую модель [4]. Кроме того, относительно толстые слои кобальта являются также барьерами и для ионов лития, которые могут преодолевать их лишь в местах немногочисленных дефектов, трещин, разрывов и утонений. Именно этим объясняется очень низкий уровень равновесной емкости таких анодов.

\section{Благодарности}

При исследовании использовалось аналитическое оборудование Центра коллективного пользования „Диагностика микро- и наноструктур“ (Facilities Sharing Centre „Diagnostics of Micro- and Nano Structures“ ${ }^{6}$.

\section{Финансирование работы}

Работа выполнена при финансовой поддержке Минобрнауки РФ в рамках государственного задания ЯрГУ им. П.Г. Демидова № 0856-2020-0006.

\section{Конфликт интересов}

Авторы заявляют, что у них нет конфликта интересов.

\section{Список литературы}

[1] Kasavaijula U., Wang C., Appleby A.-J. // J. Power Sources. 2007. V. 163. P. 1003-1039.

[2] Zuo X., Zhu J., Muller-Buschbaum P., Cheng Y.-J. // Nanomater. Energy. 2017. V. 31. P. 113-143.

[3] Mukanova A., Jetybayeva A., Myung S.-T., Kim S.-S., Bakenov Z. // Mater. Today Energy. 2018. V. 9. P. 49-66.

[4] Бучин Э.Ю., Мироненко А.А., Наумов В.В., Рудый А.С., Федоров И.С. // Письма в ЖТФ. 2019. Т. 45. В. 19. С. 17-20.

[5] Fleischauer M.D., Topple J.M., Dahn J.R. // Electrochem. Solid State Lett. 2005. V. 8. P. A137-A140.

[6] Binary alloys phase diagrams / Ed. T.B. Massalski. Materials Park, OH: ASM International, 1990. 3589 p.
[7] Ma D., Cao Z., Hu A. // Nano-Micro Lett. 2014. V. 6. P. $347-$ 358.

[8] Li H., Huang X., Chen L., Zhou G., Zhang Z., Yu D., Mo Y.J., Pei N. // Solid State Ion. 2000. V. 135. P. 181-191.

[9] Bordes A., De Vito E., Haon C., Secouard C., Montani A., Marcus P. // ACS Appl. Mater. Interfaces. 2015. V. 7. P. 2785327862. 